\title{
Let us say what we need ourselves: report of the interview of mental health service users with schizophrenia in South-West Nigeria.
}

\author{
Oyeyemi Olajumoke Oyelade ( $\nabla$ yemilad13@gmail.com ) \\ University of the Witwatersrand Faculty of Health Sciences https://orcid.org/0000-0002-0173-9208 \\ Nokuthula Gloria Nkosi \\ University of the Witwatersrand Faculty of Health Sciences
}

\begin{abstract}
Research article
Keywords: Mental health service users, Rehabilitation, Mental illness, Schizophrenia
\end{abstract}

Posted Date: November 22nd, 2019

DOI: https://doi.org/10.21203/rs.2.17697/v1

License: (c) (1) This work is licensed under a Creative Commons Attribution 4.0 International License. Read Full License 


\section{Abstract}

Schizophrenia is one of the, most chronic mental illnesses that subjects' individuals who are suffering from dictatorship and control by close associates/friends, family and health professionals. The productivity of individuals who have schizophrenia is also reduced, due to the debilitating effect of the illness. In some countries, the right of such individuals is protected by laws guiding their treatment, however in the majority of the lowmiddle income countries (64\%), Nigeria included, there are no Mental Health Acts that protect the rights of individuals in such categories. Without law or guidance, individual health professionals engage in trial and error, subjective ideas, or dictatorship. However, in a situation where recovery has been achieved, which is a function of remission of symptoms, there is a need for mental health service users to take part in their care. When a mental health service users' voice is heard and appreciated, there is a high tendency for quick improvement, and this makes rehabilitation goals achievable. This study, therefore, describes the rehabilitation activities for individuals with schizophrenia in South-West Nigeria. A descriptive qualitative approach and semi-structured interviews were used to gather information from mental health service users at the eight clinics of the two tertiary psychiatric institutions in South-West Nigeria. Twenty-nine mental health service users were interviewed. The results of the interview were analysed independently by both researchers through a content analysis approach, using NVIVO version 11. The results of the analysis were compared, and an agreement reached on the conclusion. This study revealed that there was no uniform approach to rehabilitation of individuals with schizophrenia in South-West Nigeria, and instances of dictatorship and dependence by professional on the choice of activities were eminent. For the few who were able to make an informed decision, the mental health service users did better on what they chose to do themselves than what the family and health professionals suggested. However, when the mental health service users, did what they felt was best for them; this indicated a certain level of rehabilitation. This study, therefore, encourages the development of practice guidelines for the rehabilitation of individuals with schizophrenia in Nigeria.

\section{Background}

Schizophrenia is the most stigmatised mental illness that subjects an individual and their families to reduced social desirability (Cullen et al. 2017; Lucas et al. 2018). Schizophrenia, being the most chronic form of mental illness, contributes to $7 \%$ to the global burden of mental illnesses (Funk, 2016; Alphs et al. 2018). In Africa, mental illness accounts for $18 \%$ of life lived with the disability (WHO 2012), meaning if an individual has a mental illness for 10 years, they will be utterly dependent for 730 days ( 2 years) of his/her life. Moreover, there is a 40 to $60 \%$ chance of premature deaths in people with schizophrenia (WHO, 2014). In order to provide an overview of schizophrenia, Uys and Middleton (2014) states that Schizophrenic symptoms are divided into two groups. Group one is the positive symptoms (function distorted, which involves perception, inferential thinking, thought /language, behavioural monitoring). Group two is the negative symptoms (function diminished, which involves fluency of speech/ thought, emotional expression, volition and drive, inability to experience pleasure and capacity). It is important to note that, it is the negative symptoms which impair the person's ability to function in daily life; most people with schizophrenia are unable to hold down a job in the open labour market, to form deep friendships or have meaningful intimate or family relationships (Marder \& Galderisi, 2017).

Furthermore, the experience of living with schizophrenia comes with internal and external conflict. The internal conflict can be expressed in terms of hallucinations and delusions (Gumley \& Liotti, 2018; Donaldson, et al., 2019), while the external conflict can be defined in terms of how society reacts to individuals experiencing the internal conflict (Hsiao et al., 2018). This external conflict aggravates social undesirability and sometimes leads to the homicide of people with schizophrenia, especially in Africa (Adinkrah, 2019). An individual living with schizophrenia also experiences a conflict of choice and sometimes strict directives from family and health professionals (Albrecht et al.,2019). Post recovery, some are lucky to have the opportunity to be rehabilitated to a previous setting with full family support (Seshadri et al., 2019), while some lose their family through rejection and therefore embrace being homeless, living on the streets and becoming beggars, while others live alone at a shelter and some become confined to hospital for the rest of their lives (Smartt et al., (2019). This article reports on the experiences of individuals living with schizophrenia regarding the hospital-based rehabilitation services provided to them.

\section{Methodology}

This study takes the stance that reality about rehabilitation of individuals is subjective and therefore adopted the qualitative approach to inquire about the rehabilitation of individuals with schizophrenia in South-West Nigeria. Data were collected through semi-structured interviews, which were audio-recorded, and each interview took an average of 45 minutes. The interviews were conducted by the researcher between April 2019 and September 2019 . A total of 29 mental health service users were interviewed, and the demographic description of the participants is depicted in Table 2.

\section{Research setting and participants}

This study was conducted in two tertiary institution units where individuals with schizophrenia receive follow-up care and vocational activities (rehabilitation) in South-West Nigeria. The two tertiary institutions are located within $120 \mathrm{~km}$ of each other. The first institution was established 37years before the second, which has more space and more numerous facilities.

The first institution: this has only one unit that engage in the rehabilitation of the individuals with schizophrenia and is called the Occupational Therapy Unit. The mental health service users come to this unit from home daily to engage in different rehabilitation services ranging from learning of different vocational skills (tailoring, hair dressing, shoe-making, bead-making, wool works) to behavioural (habit training) and psychosocial therapies (relationship and anger management). 
The second institution: this institution has seven units that engage in rehabilitation activities, which are grouped as total outpatient unit, intra-hospiceoutpatient unit and outreach clinics: Total outpatient unit; 1). General Outpatient unit: this unit is strictly outpatient, and is where young and middle aged adults are seen, ages 20 to 45years. 2). Psychogeriatric unit: this unit is also strictly outpatient, and is where older adults are seen, ages 46 to infinite. Intrahospice-outpatient unit: these are places where some patients stay, such as a home, after discharge from hospital and have no family home to go to (usually referred to as halfway houses within the hospital facilities). Some of these mental health service users, who reside in these houses, are employed as hospital cleaners and are on stipends, from which they pay accommodation fees (at the halfway house) and buy medication. Others are either on a pension, which is only for those who retired from government service, or are engaged in petty trade within the hospital for health professionals on duty and mental health service users on admission. These facilities are divided into three: 1). Male rehabilitation unit: this is an outpatient unit that serves as a home for several categories of males' mental health service users, including street or vagrant patients brought by Non-Governmental Organisations (NGO) or government officials, mental health service users who lost contact with relatives, indigents mental health service users and mental health service users with criminal records. 2). Female rehabilitation unit: this outpatient unit serves as a home for several categories of female mental health service users, including street or vagrant patients brought by NGO or government officials, mental health service users who lost contact with relatives, indigent mental health service users and those with criminal records. 3). Hope villa: this unit is where the mental health service users who have been discharged and are not able to live with their family anymore but have not secured a rented apartment stay. Outreach clinic: these clinics are far from the main hospital but serve as community psychiatry service centres. 1). Community service centres: the hospital has 14 community service centres that serve as primary healthcare facilities, where patients from the rural areas access clinic facilities and follow-up care. 2. State community unit: the hospital has a service centre that serves as a secondary healthcare facility, where a service user in a township can assess clinic services and follow-up care.

The participants for this study are mental health service users with schizophrenia who are discharged but receive in-hospital or outpatient rehabilitation care within the two tertiary facilities.

\section{Figure1: A schematic representation of the research setting}

\section{Sampling and procedure for data collection}

A purposive sampling technique was used to select the case file of mental health service users with schizophrenia, while file assessment and the snowballing approach was used to select suitable participants by recommendation of health professionals after sorting out the cases with eligible criteria. The first eligibility criteria was mental health service users' stability; stable mental health service users who could give information were sorted from the files of the mental health service users with schizophrenia with the assistance of health professionals, i.e. nurses on duty. The professional nurses were familiar with these patients, and their records were checked to sort out mental health service users who had been discharged for more than three months. This was because research evidence shows that the risk of relapse is usually high between 1 to 3 months of discharge (Rossi et al., 2018). Exclusion criteria included records of negative symptoms in the last three months, history of debilitating co-morbidity (such as head injury, cerebral cancer, poorly managed diabetes with injuries or wounds), affective co-morbidities, such as depression and mania, and less than 18years of age.

The details of the study (Information leaflet: Annexure A and Consent: Annexure B) was explained and given to the patient at the first clinic contact. After their consent was sought and they were informed that participation in the study was voluntary and that they could withdraw anytime they chose to, they were asked for a convenient day for the interview; they were interviewed at the patient's preferred location on their chosen date. The researcher paid for the transport of the patient, and in the situation where relatives came with them, double amount of transport money was given to the individuals. Some of the mental health service users interviewed were individuals with schizophrenia, who were employed after discharge as hospital contract employees and lived within the hospital, while some were vocational apprentices, that either lived within the hospital or came from their respective houses. Individuals that fell within these categories were interviewed after work or before the start of the day's work, as the participant preferred, such individuals were also given transport money for that day. The contract employees living within the hospital premises were interviewed in their leisure time and were thanked verbally but were not given any remuneration as they did not engage in any transportation to get to the facility; such categories were mental health service users from the Rehabilitation Unit and Hope villa.

\section{Ethical Considerations}

The first full approval was secured from the first institution on the $19^{\text {th }}$ of October 2018 with approval number: NHREC 24/07/2013/PRO 12/18, the second institution granted approval on the $30^{\text {th }}$ October 2018 with approval FNPH/HREC 18/10 and the full approval from the overall body was secured on $21^{\text {st }}$ January 2019 with approval number: M180944, after which the study commenced $1^{\text {st }}$ April 2019 and ended $1^{\text {st }}$ September 2019. Beneficence was promoted in this study, as there were no physical risks. Although the mental health service users are a vulnerable population, their rights were protected by strictly adhering to the enquiry on what this study is purposed. The inclusion criteria also considered mental health service users' vulnerability to determine those who were eligible to participate, part of which was clinical stability of three months, the evidence of which was confirmed through the follow-up report. Comorbidity with an affective disorder that increased the tendency of emotional breakdown was also excluded to minimise the emotional risk. This study posed no harm, although recounting the experience could bring about emotional reaction in individuals with schizophrenia, despite the consideration of that for exclusion, thus, the researcher, prior to commencement of the research, liaised with the Psychology Unit of the hospitals that in the event any participant broke down emotionally during or even after the data collection would be referred at the researcher's cost; this was because mental health service users pay for this service and the section will be discontinued. The researcher developed a referral slip, and the Head of the Psychology Unit approved the referral of participants, but no participant had an emotional breakdown throughout the course of the study.

\section{Trustworthiness}

The trustworthiness of this study was achieved by obtaining informed consent of the participants, which indicated the audio-recording. Other efforts to achieve trustworthiness are described below. 
Credibility: For this study, credibility was achieved as follows:

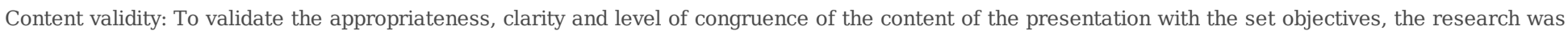

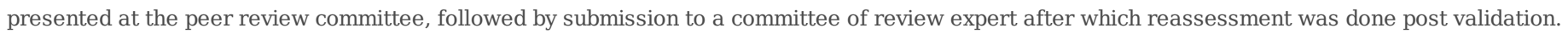

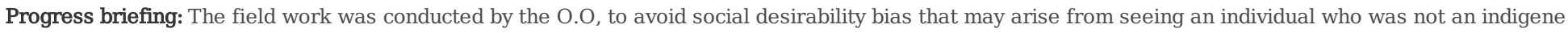

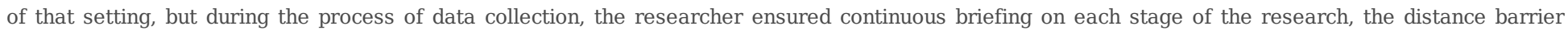

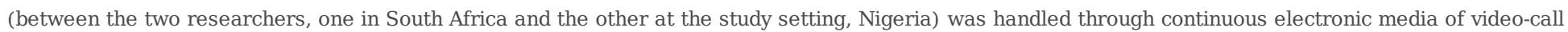
communication.

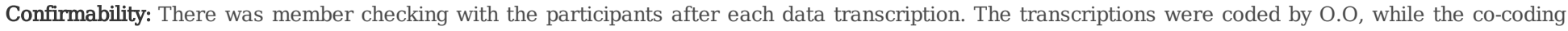
was done by N.G after which the transcript was exported to NVIVO and analysed.

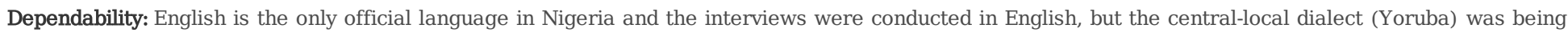

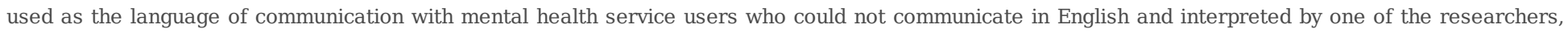

O.O.

Transferability: In the findings, the authors ensured a detailed expression of all the stages of the study.

\section{Data analysis}

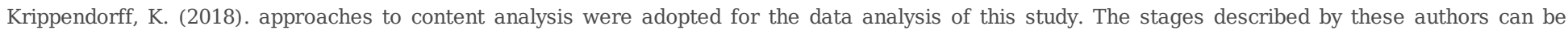
summarised into three phases: preparation, collation and report.

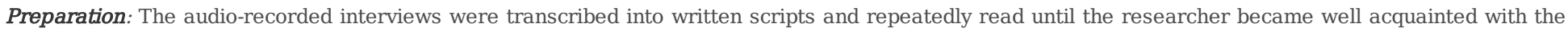
content of the transcribed scripts.

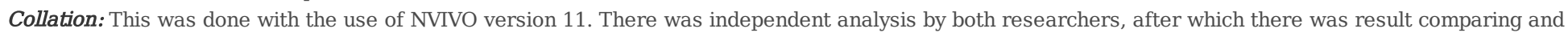

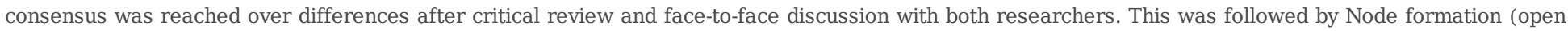

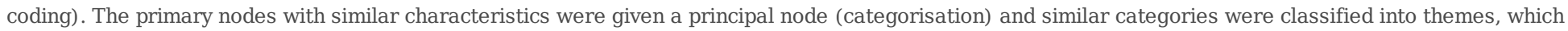

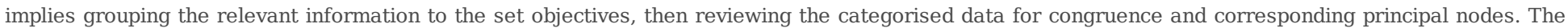

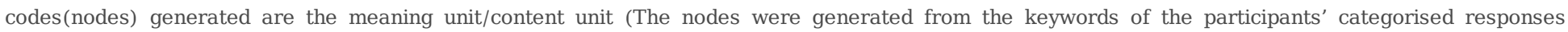
(condensation). In short, there was verbatim transcription onto coding sheets, while themes and categories were generated.

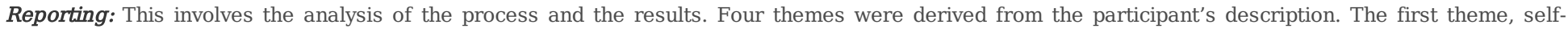

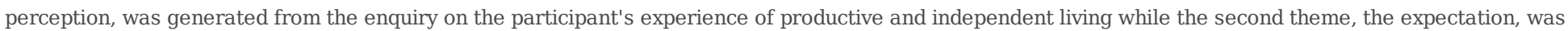

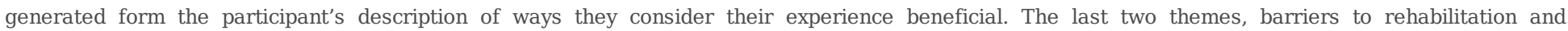

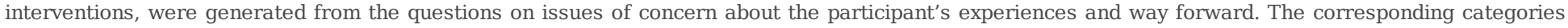
and the themes derived are presented in Table 1.

Table 1: The themes and corresponding categories

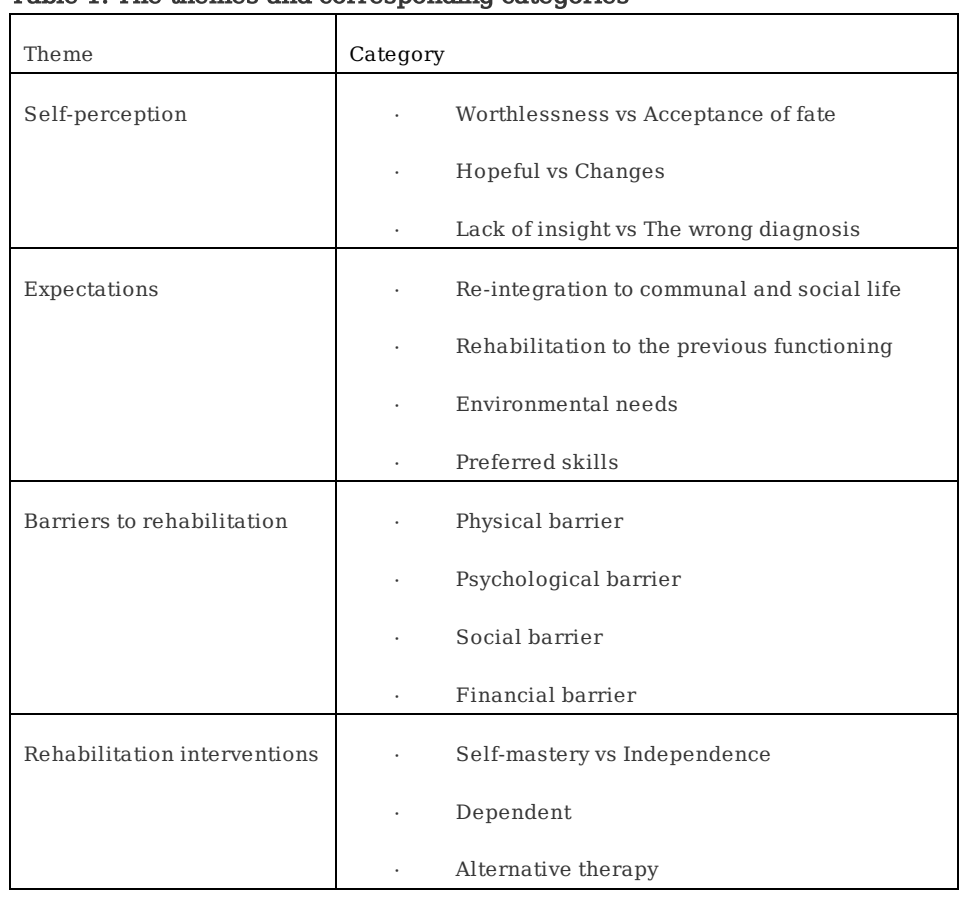

\section{Results And Discussion}




\begin{tabular}{|c|c|c|c|c|c|c|c|c|c|}
\hline $\mathrm{S} / \mathrm{N}$ & Unit & Age & Sex & Diagnosis & $\begin{array}{l}\text { Experience with } \\
\text { schizophrenia in years }\end{array}$ & $\begin{array}{l}\text { Experience with } \\
\text { rehabilitation in years }\end{array}$ & Activity before illness & Activities after illness & $\begin{array}{l}\text { Remark(Alone or with } \\
\text { relatives) }\end{array}$ \\
\hline 1 & $\begin{array}{l}\text { Psychogeriatric } \\
\text { Unit }\end{array}$ & 60 & F & Schizophrenia & 18 & 18 & $\begin{array}{l}\text { Business (Major } \\
\text { distributor of rubber) }\end{array}$ & Daily house cleaning & $\begin{array}{l}\text { Accompanied } \\
\text { by relative }\end{array}$ \\
\hline 2 & $\begin{array}{l}\text { Psychogeriatric } \\
\text { Unit }\end{array}$ & 61 & F & Schizophrenia & 20 & 20 & Retired typist & Daily house cleaning and cooking & $\begin{array}{l}\text { Accompanied } \\
\text { by relative }\end{array}$ \\
\hline 3 & $\begin{array}{l}\text { Psychogeriatric } \\
\text { Unit }\end{array}$ & 73 & F & Schizophrenia & 40 & 2 & Food vendor & Daily house cleaning & $\begin{array}{l}\text { Accompanied } \\
\text { by relative }\end{array}$ \\
\hline 4 & $\begin{array}{l}\text { Psychogeriatric } \\
\text { Unit }\end{array}$ & 59 & F & Schizophrenia & 20 & 5 & Caterer & Nanny (Baby-sitting) & $\begin{array}{l}\text { Accompanied } \\
\text { by relative } \\
\end{array}$ \\
\hline 5 & $\begin{array}{l}\text { Psychogeriatric } \\
\text { Unit }\end{array}$ & 70 & F & Schizophrenia & 50 & 20 & Petty trader & Daily house cleaning and cooking & $\begin{array}{l}\text { Alone, } \\
\text { not accompanied }\end{array}$ \\
\hline 6 & $\begin{array}{l}\text { Psychogeriatric } \\
\text { Clinic }\end{array}$ & 60 & F & Schizophrenia & 10 & 6 & Petty Trader & Little house care with paid house help & $\begin{array}{l}\text { Accompanied } \\
\text { by relative }\end{array}$ \\
\hline 7 & $\begin{array}{l}\text { Rehabilitation } \\
\text { Unit } \\
\end{array}$ & 64 & M & Schizophrenia & 24 & 10 & Native doctor & Self-care-grooming & \begin{tabular}{|l} 
In-house \\
No relatives
\end{tabular} \\
\hline 8 & $\begin{array}{l}\text { Rehabilitation } \\
\text { Unit }\end{array}$ & 69 & M & Schizophrenia & 15 & 10 & $\begin{array}{l}\text { Primary school Cert } \\
\text { Holder }\end{array}$ & Hospital Cleaner & $\begin{array}{l}\text { In-house } \\
\text { No relatives }\end{array}$ \\
\hline 9 & $\begin{array}{l}\text { Rehabilitation } \\
\text { Unit } \\
\end{array}$ & 64 & M & Schizophrenia & 12 & 9 & Mechanic & Hospital Cleaner & $\begin{array}{l}\text { In-house } \\
\text { No relatives }\end{array}$ \\
\hline 10 & $\begin{array}{l}\text { Rehabilitation } \\
\text { Unit }\end{array}$ & 50 & M & Schizophrenia & 10 & 10 & Carpenter & Self-care & $\begin{array}{l}\text { In-house } \\
\text { No relatives }\end{array}$ \\
\hline 11. & $\begin{array}{l}\text { Rehabilitation } \\
\text { Unit }\end{array}$ & 70 & M & $\begin{array}{l}\text { Paranoid } \\
\text { Schizophrenia }\end{array}$ & 35 & 30 & Carpenter & Hair dressing and In-house Petty Trade & $\begin{array}{l}\text { In-house } \\
\text { No relatives }\end{array}$ \\
\hline 12 & $\begin{array}{l}\text { Rehabilitation } \\
\text { Unit }\end{array}$ & 71 & M & $\begin{array}{l}\text { Paranoid } \\
\text { Schizophrenia }\end{array}$ & 42 & 41 & School Cert Holder & Hospital Cleaner & $\begin{array}{l}\text { In-house } \\
\text { No relatives }\end{array}$ \\
\hline 13 & Hope Villa & 63 & M & \begin{tabular}{|l} 
Paranoid \\
Schizophrenia \\
\end{tabular} & 15 & 19 & School Cert Holder & Sells Research Card & $\begin{array}{l}\text { Private Hospital } \\
\text { Residence }\end{array}$ \\
\hline 14 & Hope villa & 64 & F & Schizophrenia & 30 & 4 & Retired Teacher & Hospital stock shop keeper & $\begin{array}{ll}\text { Private Hospital } \\
\text { Residence }\end{array}$ \\
\hline 15 & $\begin{array}{l}\text { Rehabilitation } \\
\text { Unit }\end{array}$ & 43 & $\mathrm{~F}$ & Schizophrenia & 15 & 5 & $\begin{array}{l}\text { Housewife } \quad \text { (Home- } \\
\text { manager) }\end{array}$ & Hospital Cleaner & $\begin{array}{l}\text { In-house } \\
\text { No relatives }\end{array}$ \\
\hline 16 & $\begin{array}{l}\text { Rehabilitation } \\
\text { Unit }\end{array}$ & 22 & $\mathrm{~F}$ & Schizophrenia & 6 & 6 & JSS3 Holder & Hospital staff Vehicle cleaner & $\begin{array}{l}\text { In-house } \\
\text { No relatives }\end{array}$ \\
\hline 17 & $\begin{array}{l}\text { Occupational } \\
\text { Therapy Unit }\end{array}$ & 48 & $\mathrm{~F}$ & Schizophrenia & 20 & 20 & Pharmacist & Tailoring apprentice & $\begin{array}{l}\text { Alone, not } \\
\text { accompanied }\end{array}$ \\
\hline 18 & $\begin{array}{l}\text { Occupational } \\
\text { Therapy Unit }\end{array}$ & 60 & M & Schizophrenia & 20 & 15 & University Graduate & Hair dressing & $\begin{array}{ll}\text { Alone, not } \\
\text { accompanied }\end{array}$ \\
\hline 19 & $\begin{array}{l}\text { Occupational } \\
\text { Therapy Unit }\end{array}$ & 59 & F & Schizophrenia & 30 & 29 & House help & Leisure walk & $\begin{array}{ll}\text { Alone, not } \\
\text { accompanied }\end{array}$ \\
\hline 20 & $\begin{array}{l}\text { Occupational } \\
\text { Therapy Unit }\end{array}$ & 35 & M & Schizophrenia & 32 & 32 & $\begin{array}{l}\text { Graduate-Public } \\
\text { administration }\end{array}$ & Hair dressing apprentice & $\begin{array}{l}\text { Alone, not } \\
\text { accompanied }\end{array}$ \\
\hline 21 & $\begin{array}{l}\text { Occupational } \\
\text { Therapy Unit }\end{array}$ & 34 & M & Schizophrenia & 22 & 22 & School cert Holder & $\begin{array}{l}\text { Wool work(Knitting) } \\
\text { apprentice }\end{array}$ & $\begin{array}{l}\text { Alone, not } \\
\text { accompanied }\end{array}$ \\
\hline 22 & $\begin{array}{l}\text { Occupational } \\
\text { Therapy Unit }\end{array}$ & 57 & M & Schizophrenia & 40 & 37 & Real Estate Management & Learning Computer & $\begin{array}{ll}\text { Alone, not } \\
\text { accompanied }\end{array}$ \\
\hline 23 & $\begin{array}{l}\text { Occupational } \\
\text { Therapy Unit }\end{array}$ & 42 & M & Schizophrenia & 10 & 2 & $\begin{array}{ll}\text { Funnel } & \text { taker/Office } \\
\text { Assistant } & \\
\end{array}$ & Learning Computer & \begin{tabular}{|l} 
Alone, not \\
accompanied
\end{tabular} \\
\hline 24 & $\begin{array}{l}\text { Occupational } \\
\text { Therapy Unit }\end{array}$ & 37 & M & Schizophrenia & 32 & 32 & Primary school Cert & Hair dressing apprentice & \begin{tabular}{|l} 
Alone, not \\
accompanied
\end{tabular} \\
\hline 25 & $\begin{array}{l}\text { Occupational } \\
\text { Therapy Unit }\end{array}$ & 35 & M & Schizophrenia & 10 & 9 & $\begin{array}{l}\text { Graduate-Business } \\
\text { Administration }\end{array}$ & Tailoring apprentice & $\begin{array}{l}\text { Alone, not } \\
\text { accompanied }\end{array}$ \\
\hline 26 & $\begin{array}{l}\text { Occupational } \\
\text { Therapy Unit }\end{array}$ & 61 & M & Schizophrenia & 22 & 10 & Quantity Surveyor & $\begin{array}{l}\text { Different units-from tie and dye to shoe making, to } \\
\text { tailoring, now computer }\end{array}$ & $\begin{array}{l}\text { Alone, not } \\
\text { accompanied }\end{array}$ \\
\hline 27 & $\begin{array}{l}\text { General } \\
\text { Outpatient } \\
\text { Unit }\end{array}$ & 56 & F & Schizophrenia & 10 & 7 & Fashion Designer & Fashion Designer & $\begin{array}{l}\text { Alone, not } \\
\text { accompanied }\end{array}$ \\
\hline 28 & $\begin{array}{l}\text { General } \\
\text { Outpatient } \\
\text { Unit }\end{array}$ & 27 & M & Schizophrenia & 5 & 2 & University Graduate & Shop keeper & $\begin{array}{l}\text { Alone, not } \\
\text { accompanied }\end{array}$ \\
\hline 29 & $\begin{array}{l}\text { Community } \\
\text { Service Centre } \\
1\end{array}$ & 28 & M & $\begin{array}{l}\text { Schizo-affective } \\
\text { disorder }\end{array}$ & 15 & 1 & Farmer & Farmer & $\begin{array}{l}\text { Alone, not } \\
\text { accompanied }\end{array}$ \\
\hline
\end{tabular}

Table 2 above indicated an overview of the participants' demographics, which reveals the number of males was seventeen (17), and twelve (12) females, which is consistent with the fact there are more men living with schizophrenia than women, as declared by Lim (2017). This is also consistent with the 
declaration of Seeman (2018) who's review study discovered schizophrenia was more common in men than women, with the reason that male and female DNA is exposed to different environmental input which differentiates level of predisposition to schizophrenia. In summary, we discovered that the

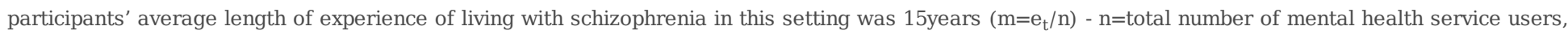
$\mathrm{e}_{\mathrm{t}=}$ experience in years. The four themes that emerged from the results are discussed below.

Code interpretation: All codes had C, A or L, which are: C signifies the client, the number is the sequence of the interview, then the name of the hospital, A is for the first tertiary institution and L is the second, followed by the name of the unit, e.g. C4AG is the fourth client at A hospital and G signifies geriatric unit.

\section{Theme 1: Self-perception}

The theme self-perception was generated from the participants' self-description. This consisted of three categories, Worthlessness vs Acceptance of fate, Hopeful vs Change, and Lack of insight vs The Wrong diagnosis.

The researchers during data collection observed that some of the participants had a feeling of worthlessness:

C4Ag, who shook her head, hissed and said....... - "I cannot even do anything, not even clean the house, just there sitting down. When I try to wash the toilet, I will see many things that made me sick; I see different things."

Another participant, C3Ar, expressed the feeling that she is unwanted with a gesture of displeasure and the way she opened her hands like she wants to throw something away and said...... - "My mother does not want me again...Nobody asks of me. They abandoned me......they got rid of me."

Conversely, participant $C 2 L$, who seemed to think that the feeling of worthless disappeared due to his ability to do something with his life said - "It has been difficult passing through this road. I have idea, but staying at home and doing nothing, taking medication, eating, sleeping and all that" .... and he continued to say - "Right now, I am in order, doing well, now at Occupational Therapy Unit, I am into knitting, so as I progress further.... I no longer feel idle as I use to feel before I started coming here."

While some participants felt that their self-perception was a product of how others viewed them, which also made them deny their illness and perceived themselves to be victims of how people perceived them before they were admitted for treatment.

Participant, C11Ar, looked away as he said - "They said we are sick and want us to believe that we are sick, so we are here now receiving treatment because they said we are sick."

C11Ar, further explained thus; "I was at my duty post when the co-workers took me to a health centre, and it is the nurses at the health centre that brought me here. They said l am sick. My family came for a while, and later they stopped coming."

C1Av believed he was wrongly diagnosed and said with a tone of firmness - "I have malaria, not a mental illness." This mental health service user further explained; "I was referred from a private hospital, where I was diagnosed of malaria, the first time I came, the referral letter was sealed and what I was told is that where I was referred to is a specialist hospital and that I should never open the letter but give it to the health professionals there, they told me I would be better managed."

C10Ar shared the same belief of the wrong diagnosis ...- "I have a problem of bird heart" .......as he continued in the discussion the issue came up again and he re-emphasised......." I have a problem with the heart; I told you my heart is like that of a bird."

\section{Discussion}

Self-perception in our study revealed participant's perceived themselves as worthless, related to inactivity and a product of what people thought about them, leading to their loss of sense and being. This is consistent with findings of Askari (2018), who found that inactivity was a potential and actual cause of mortality in schizophrenia. Again, self-perception in this study was the feeling of uselessness through rejection or abandonment in the hospital. According to Loh (2018), Hasan and Adil (2019), and Moorkath et al. (2019), the feeling of uselessness, is the reactions individuals with schizophrenia experience from family. Moorkath et al. (2019) discovered that families abandon relatives with schizophrenia for many reasons ranging from avoidance of labelling of the family name, to burden of care and feeling of hopelessness. Hasan and Adil (2019) stated families abandon people with schizophrenia to protect their social outlook and financial status. In Loh's (2018) view, in their study conducted in developing countries, schizophrenia constituted a cause of attention and family distress, and families abandon individuals living with schizophrenia to reduce their own stress and burden.

Noteworthy in this study, in relation to self-perception, was a defective insight of some of the participants about their diagnosis. These participants have been admitted in the hospitals for about 30 years and on rehabilitation for 20years. The expectation is that they would have some level of insight or sense of identity, not only because of rehabilitation services but pharmacotherapy, however lack of insight was significant among our participants. This lack of awareness of their own diagnosis is evident where the participant reported he was diagnosed with malaria, and the referral letter was kept secret only to be told later that he suffers from schizophrenia. This patient depended on the people he trusted, the health professionals, to be open and honest from the beginning about his condition however this planted a sense of doubt about the diagnosis of schizophrenia for more than 20 years. This is consistent with the findings of Amsalem et al. (2018), where it was reported that the attitude of health professionals towards the disclosure of schizophrenia diagnosis significantly impacts on acceptance of the diagnosis by both mental health service users and their relatives. Literature also indicates that lack of insight can impede productivity, and achievement of insight should be the first step towards rehabilitation (Jong et al., 2019). Sánchez et al. (2019) also declared that the inability to accept disability was a significant barrier to individual productivity and social functioning.

Theme 2: Expectations

The participants' expectations were what they wished to do with their life. In a bid to rehabilitate C1Av, who was one of the participants who resided in the hospital private lodge, Hope Villa, he was employed as a cleaner in the hospital and sells recharge cards within the hospital, but he said he felt as though he was in bondage, being confined to the hospital due to neglect by family. He also had a passion for singing but lacked opportunities. "Music is the only other thing I could think of, I like singing, and I loved to go to the studio and record the songs I have composed, but I have nobody to help me. I also sing in church. I have composed many songs, but nobody to help me." Participant C1Av was asked to sing, and he sang one of his tracks titled "There are many 
people in bondage.' C1Av sang beautifully and the researcher during the data collection had to be aware of her emotions and only just managed not to cry. The song was so melodious, emotion-provoking and educative. He spoke about his experiences and life history succinctly and appealingly. This is an excerpt from his song:

"There are many people in the bondage...............they never wish to be in bondage, many see them afar and judge them......not knowing that they have their story................

Each individual has a story.......... You can only know if you ask them or care to know......

Their story may not be known if you do not ask.........

They never also want to be in bondage....... They have a story to tell but ask them.

Do not just judge people from far, but ask them............. Ask them to know about their story. Not judge from afar."

Some other participants who also stayed at the hospital residence said, their utmost desire was to go home. C7Av lives at a Hope Villa, and manages a stock shop owned by the hospital, but desires to go home.

C7Av said it is a taboo to die outside your domain by stating that: "Well, you know it is not good for someone to go without coming home. May we not die in a foreign land."

Another participant, C12Ar, mentioned he also resides in the hospital intrahospice-outpatient ward, was employed as a hospital cleaner and said all he wants is to go home: "They should make an effort to assist me to return home when my people come."

C9Ar, also wanted to go home - "I have been here for long. My relatives no longer come. The boss here, the ward manager, did not tell me the plan for me. Our boss here, she never tells me when I will be discharged and go home."

Three outpatient participants who accessed the rehabilitation service at the hospital's Occupational Therapy Unit also expressed desires that were different from the facility pursuit for them.

Participant C6L, who attends occupational therapy expressed her desire, with a low voice and looking down, as "I am learning tailoring here, but what I want is for them to help me to achieve going back to my school and graduating, and after, I will have some work to do." Clearly this patient did not think the vocation taught to her was helpful, but education was. This participant further explained that "I stopped at 300 level as a pharmacy student."

Another participant, C9L, also attending O.T. declared similar views, "I am into barbing (hair dressing) section here, learning barbing (hair dressing), but my aspiration in life is to become an administrative person, working for the government. I studied business administration at university and that's what I want to do. I like meeting people." He was further asked if he had received assistance in regard to his desire and he responded thus, "No. No assistance. I am doing it myself. I also want to establish a business and I want to go back to school. I want to go and do my Masters post-graduate......"

C5L described how his choice of career was decided for him by others, "Actually, when I came, I was directed to the tailoring section by former H.O.D. I worked there for about three years. There I couldn't, I was not able to pass thread into the needle. So, I had to go for an eye test. So, I was recommended a pair of glasses. Later on...they, my colleagues in the tailoring section, inform me that I should go for computer training. I am here now for about 6 years. Here I learnt how to make use of computer especially, Corel Draw, Microsoft Word, Microsoft Excel and so on." The participant was asked by the researcher why they asked him to go for computer lessons, but he said; "I do not know the reason they gave, but they said its better I go there, just to conclude my rehabilitation." He further said, "At this computer age, I would like to be a computer analyst, because it is a thing of............... ehn............ a thing of................computer age."

Another participant, C7L, said he was told to learn computer, the researcher observed that he looked less interested. "I was told I have to come here and be learning somethings. So................. (The participant did not conclude the statement he just ended with so, but the researcher asked, so what? He continued and said, "So I learned it").

\section{Discussion}

This study revealed that the participants' passions contradicted with what they were trained to do, and some participants felt compelled to do activities that did not yield a positive result. This was consistent with the findings of Corbière et al. (2019), that dictatorship can serve as a significant constraint to the productivity of individuals with psychiatric conditions. Souraya et al. (2018) also revealed that giving individuals living with schizophrenia liberty to make an informed decision was vital in goal-orientated rehabilitation. Asher (2018) also asserts that individuals with schizophrenia do well in the choice of career or rehabilitation activities if the choice was self-initiated or self-driven. Asher (2018) declared that even if the choice of career was made by the mental health facility users, unsolicited monitoring by family and professionals should be avoided. The same author (Asher, 2018) suggests ways to avoid dictatorship and monitoring by professionals and family as firstly - Family education or family therapy, secondly - rehabilitation should be conducted by non-health professionals. The reasons Asher (2018) gave for this was that health professionals relationship with individuals with schizophrenia follows paternity paradigm and it may be difficult for a health professional to engage in change of paradigm during rehabilitation. While Asher (2018) suggested training of volunteer unskilled workers for rehabilitation, Lempp et al. (2018) revealed individuals who have a history of schizophrenia, and are successfully rehabilitated, are best suited for this purpose. Lempp et al. (2018) says when mental health service users facilitate the rehabilitation programmes, it has amazing benefits in correct channelling of such programmes and guidance of participants with goal setting. Rai et al. (2018) also reported another benefit of mental health service users' involvement in rehabilitation by declaring that mental health service users co-facilitated training reduces the stigma of mental illness. A three-year peer support service among individuals with mental illness in China revealed the active participation of mental health service users serves, through therapeutic use of one another, as a role model for the new clients of recovery goal and rehabilitation service (Fan et al., 2018). This study was able to gather that the rehabilitation plan and choice of activities was directed by health professionals. This study, therefore, takes the stance that, the involvement of non-skilled professional or mental health facility users in facilitation of rehabilitation programmes may reduce the hierarchy of using health professionals, as declared in WHO mental health action plan (WHO, 2013). Looking at the demographic profile of the time the participants have been on rehabilitation and reportedly learning a trade for years, but there seems to be no end to rehabilitation as compared with what operates in other settings of the world, such as Ethiopia where the individuals have the liberty to establish on their own without health professionals monitoring other than consultation as the patient desires (Asher et al.,2018). There also seems to be no objective of rehabilitation or end-goal in this setting, whereas goal setting is vital for successful rehabilitation (WHO, 2018). 
Theme 3: Barriers to rehabilitation

The barriers related by the participants were physical, structural (housing), and psychological. In terms of physical barriers, the participants recounted that there were barriers to their functioning as much as they wished they were not. During data collections, the researcher observed that one participant was shaking during the process of the discussion. The participant, C15Ag, complained by herself about the shaking of her hands as a physical barrier to her productivity by saying. - "My hands always shake; I don't know; maybe the medication I am using" ...she progressed to say that..... "I do not want my children to give their children to a nanny"..... "So I can care for their children, but my hands shake. My hand is always shaking".

On another occasion, in the researcher's account of the field experience, on the way to the field the researcher stopped at a shop to buy toiletries, but on arriving at the intrahospice outpatient unit(Hope villa), the same person who attended to her the previous day at the stock shop was the same person that was introduced as one of the individuals living in hospital facility and diagnosed with schizophrenia. The researcher deliberated on why the individual was still in the hospital house. During the interview, C7Av- expressed her lack of a physical structure (home) "I was brought back to the hospital by the social workers, when the house I was to be discharged to was dilapidated. There is no kitchen; there is no toilet; there is no water. I do not even think anyone stays there anymore" This participant experienced the challenge of housing, where would she go back to even after being functionally rehabilitated. This could possibly lead to stress.

Another barrier was psychosocial, as expressed by some participants.

C15Ag, said, "My sister from the same parent was dating my husband after I came down with mental illness....... We divorced after that, but I want us to come together again, but my sister wishes me dead." She expressed this with a blunt affect, but her words sound weighty, and went on to say, "My sister, the same father, the same mother." When she was asked if she needed support, she responded by saying, "It was so difficult, but my mother is supportive, my mother is always there to support me." The psychological distress this participant experienced seem to be hindering her will to be rehabilitated. Linked to psychosocial barrier is the social undesirability by people in the community as expressed by these participants with a history of murder. C13Ar, murder case as expressed by him, "I mistakenly killed my father" ..., "I have changed, but they do not want me at home. I have been here for 38years. "In further enquiries with him, C13Ar further revealed that he was biased that they could kill him at home, "There was a time I was discharged to my cousins house, so many families don't want me," C13Ar further recounted that the hospital social workers went back home with him, "The social workers went home with me, to the family house where I was rejected, but they told them frankly that they can't help me, they said they could not accommodate me there, that they are aware of my murder case. If I decided to stay there by force, they could kill me."

Another participant, C1Av, stated, "Ehm I had some domestic problems that involved my Dad and my mother and the rival of my mother. They all created the problem that resulted in me murdering of my father." He further said, "I took a knife and stabbed my father three times from the back, and he collapsed." In his recount C1Av further reported, "I have been there since..... I came here in 1985 from the prison. I was given amnesty by the governor of the state in 2007 October 10" "Though I helped them, they do not want me at home."

Clearly, these participants would have a significant barrier in being rehabilitated to the community, especially with their families. Without trust and a sense of belonging, it would be a challenge that the health professionals would need to work towards as a goal for rehabilitation.

\section{Discussion}

The physical barrier was attributed to medication reaction by participants in this study. However, the WHO (2013) encourages informed decision and collaboration with patients in prescription. In a self-reported study, Son (2018) declared that individuals' post-acute phase of psychosis does not necessarily have to be on regimented medication before recovery is achieved, and appraisal of individuals' needs for recovery is evidence-based and outweighs the use of medication. Flore et al. (2019) also expressed that the use of antipsychotics produces different narratives, in different individuals, that is highly subjective and should be taken as such. This study, therefore, takes the stance that physical challenges that result from medication could be avoided or better coped with if the mental health service users are allowed to make a choice on the medication preference and adhere to the choice.

Some participants in this study reported crime and social undesirability as barriers to community rehabilitation, which is equally consistent with the findings of Chen et al. (2018) that the public feel threatened by the presence of individuals with a history of schizophrenia coupled with violence. Jovanovic et al. (2019) reported that most cases of suicide and homicide occur in paranoid schizophrenia, which is consistent with the current findings. This study believes individuals who experience rejection of any type need psychological support to be able to cope with the challenges they face and re-invest their energy into productive activities; also family members of these individuals need to be educated on the type of schizophrenia experienced by their family member and linked to their behaviour prior to diagnosis. The participants in this study indicated a will to return home, but the fear of rejection or being punished for their wrong doing or even finding no house to go back to; in this instance, in a country like Nigeria with poor resources, accommodation that is structured for such individuals should be considered at a reasonable price.

Theme 4: Interventions

These are support and rehabilitation services that the individuals with schizophrenia received to enable them live an independent and productive life. 
C15Ag's description of her activities revealed that she gained self-mastery through self-initiated (internal) motivation, she said, "We sell provision, eggs, beverage, toiletries, I share the same shop with my mother".

C16Ag in her account, also reported how she has been living an independent life, "I am living alone in my room, I do everything myself, and I use my medication as prescribed, one tablet in the morning and once at night. I come to the clinic alone."

Another participant, C12Ar, who lives in the hospital residence reported, "I have been here doing one thing or the other. I have been doing a menial job. I barb (shave people's hair) and do all those small chores." He further stated, "I go out very well. The goods I sell; once sold, I go out to buy more stock myself." "I go to buy things I sell, I buy medications from the sales I make and any little amount that I get, I will add to it. That is how I have been managing myself." C12Ar further said he sells sachet water, "I also sell pure water(satchet water) using the hospital fridge. I put it in the hospital fridge."

$\mathrm{C} 1 \mathrm{Av}$ who left the inpatient ward and now resides in the hospital residential house said, "I left this place since 2010. I stay at Hope villa.... I have just come here to do business." He further stated, "I sell cell-phone recharge card to the nurses and the doctors."

CR12Ao, in her report, said the only way the illness affected her was that she could not multi-task as she used to, "I retained or continued the same job I was doing. I am a fashion designer, and that is the same thing I have been doing until now." She further stated, "The only thing is that I wanted to start water supply business, but I could not cope because I need to wake up early morning for supplies; one day I dose off and lose my wallet, so I stopped and faced tailoring squarely."

Some participants reported hospital intervention in two ways, through menial job or training. The participants who have a menial job with the hospital are those living within the premises, while those who are trained are those who come from home and could afford the cost of the training.

The seven participants who reported doing the menial jobs for the hospital are as follows:

C8Ar said, "The hospital gives us a menial job, we clean windows and sweep the floor every morning."

C9Ar- reported, "I just..... We work at secretariat there. We use to go there every morning, and we come back early, around 10 or 11, we will return from work."

C11Ar recounted, "We wash the floor. We sweep the floor. The authority employed us as cleaners."

C13Ar on his account said, "For now, they got a particular job for us to help us." He was asked what kind of job and he further said, "Cleaning Job. We clean the offices. That is what we do."

C1Av said; "I clean office. I also clean wards."

C3Ar reported that, "Every day after we sweep they give us money from the hospital bank."

C2Ar said, "I am into cleaning, cleaning and dusting".

Participant C3Ar reported how she obtained extra money, "I also wash clothes for people...... I can wash car, clothes, plates and I can also sweep the floor." Another participant, C13Ar, talked about the salary, "It is this salary that we use to maintain ourselves. Its 200naira per day (8Rand O.5/USD)."

Conversely, participant C7Av reported that she also renders service to the hospital, but she is not on a salary from the service, "I pay for my expenses through pension money." In her further explanation, C7Av seemed unhappy about the fact that she is not paid as she further said, "Ah... We get there before 9 am and close by $5 \mathrm{pm}$, what is not good is that we make good sales, but not paid any salary." "Others that work for the hospital are paid, but we are not that is not good enough, but I am praying about it."

The participants who were trained reported their training experience in two categories (Self-mastery, Dependent)

Some said they chose what to learn by themselves and they were happy doing it (Self-mastery).

C6L- said; "I have been receiving training in tailoring section. I prefer tailoring. I was the one that chose the tailoring." C6L further said she had passed through many sections, "I think they have been helping me so much in the O.T that I have been attending...the exercises. The sections, the kitchen rehabilitation...ehn...all those...and the computer, the salon, the hair salon. The tailoring section and the catering section, where I have been. I have passed through all of them. I think the way they are helping is that they have been training me towards my future goal." She was asked about her future goal, which she said was to have a tailoring firm.

Those whose choice of vocation was decided by others indicated accordingly (Dependent).

While some said they felt they had no choice (Dependent), they had a different agenda, which was personal, C9L said, "Ahm... in the department what I am into is barbing (hair dressing), they suggested it for me. I desired to become an administrative person. So, but since I am here, I have no choice. That is, it."

C1L said, "I am into tailoring, I have learnt measurement, I have learnt to spread, but it remains to sow."

Some participants in their description of the first line of family intervention said they were taken to traditional houses where they experienced abuse of all kinds. The report of C12Ar explains, "My father took me to the house of an herbalist when I was supposed to come for the second appointment, even though I told him to bring me to the hospital, but he said I should remain there. They tie me on the floor to a tree in the bush. They killed fowl and goat. They killed many animals for sacrifice. It was during that second episode of relapse that I injured someone, and the person died."

Another participant shared a similar experience, C13Ar said, "It was once I came before. Before then, I did not know about this place. I was only here for once. This is my second time. After the first time, they had no money to bring me back to this place, so they carry me to herbalist house because my people are poor and they tied me down there doing many things. After that, I had a misunderstanding with my father during which I mistakenly killed him." 
Discussion

The interventions in this study range from basic to vocational skill acquisition activities and traditional care.

The participants who were able to earn a living through paid vocational task expressed self-mastery and responsibility for self-expenses. They were able to pay their bills and live a meaningful life. This is consistent with the findings of Evensen et al. (2019) that when individuals with schizophrenia are on paid jobs, it boosts their morale, helps in rehabilitation and increases the quality of life. Although the participants in this study were earning less than 1 dollar per day, they looked more satisfied than those who come on outpatient basis and are completely dependent on their family.

This study further reveals that some participants reported cases of abuse at the home, such as chaining to a tree in the bush and beating, and reporting they became aggressive after their release. This is consistent with the report of Oyelade and Ayandiran, (2018) that aggression breeds aggression, but the victim of the retaliated aggression may not necessarily be the perpetrator. It is also noteworthy that those whom these individuals killed were not necessarily those who tied and bit them. This study, therefore takes the stance that abuse against an individual with mental illness should not be permitted and should attract sanctions. Communities need to be educated on the issues of mental illness and how to respond when someone behaves in a way that is out of their norm, even though traditional belief systems influence health seeking behaviour, it is critical to educate the community on the benefits of consulting the hospital for mental health care.

Researchers' Reflexivity

To the best of our knowledge, this is the first study in Nigeria, and not just the South-West, that involved interviews of mental healthcare service users. The researchers validated this declaration by the preliminary search of all the databases to see if there was any previous work that was done in this regard and how, but the result of the search showed that there was none. Studies found were either retrospective studies that accessed case files or enquiries from health professionals, but none that involved patient interviews. The uniqueness of this study in Nigeria was also because the participants were individuals diagnosed with schizophrenia. The two researchers are mental health nurses, but had different opinions about the group of the participants to incorporate into this study among mental health service users. The first researcher, O.O., initially expressed a bias about individuals living with schizophrenia and feared about their suitability for an interview, while the second researcher, N.G., said the stable individuals could be interviewed and would be able to give information. These two researchers are different African Nationals, the first is a Nigerian and the second is a South African. Their nationalities became a point of attention in view of the different ideology about interviewing the individuals with schizophrenia. South Africa has conducted a study on rehabilitation, which involved interviewing individuals with schizophrenia, but none exists in Nigeria. South Africa has a mental health action plan, but mental healthcare in Nigeria is still guided by the Lunatic Act of 1958, the procedural element that gives room for abuse and subduing of individuals with schizophrenia and mental illness in general. The researchers, after a serious deliberation with pieces of evidence from the interviews of individuals with schizophrenia in other countries, both agreed on the conducting of this study. In the process of securing approval at the research site, concerns were raised about whether the participants, individuals with schizophrenia, would be suitable to give information, but with the researchers' explanation of the process of selection, approval was granted. The fact that the participants were able to express themselves coherently and clearly disproves the fear of whether individuals with schizophrenia can or cannot give information clearly and coherently about themselves in interviews. The preconceived idea expressed by the first researcher, who is a Nigerian and at one of the two tertiary institutions, is an indication of national bias. which is evident in the Lunatic Act of 1958 that guides mental healthcare in Nigeria. Therefore, the development of the Mental Health Policy in Nigeria may have a long way to go in reducing biases and stigma of mental illness.

\section{Conclusion}

The purpose of the study was to describe the experience of individuals with schizophrenia on rehabilitation. In this study, this was achieved by finding out their experiences of acquisition of vocational skills, employment in hospital facility, entrepreneurial activities and family dependence. Through the study it was found that those who were not dependent on health professionals were able to live independently, regardless of the illness. From the findings of this study, the conclusion was drawn that individuals who have been neglected by relatives and confined to hospital expressed high decision-making capacity and could pursue their desire compared those who have support services from families. Those individuals, who go home and come to assess rehabilitation practices on an outpatient basis, are subjected to dictatorship from family members and/or health professionals. The constraints generally expressed were funds for business establishment. Those who were confined to the hospital also desired to be reintegrated to the community. Conversely, those who had family support declared that what they needed from society was support in areas where they expressed needs. With regard to the health professionals' interventions, this study noted wide variations between the approaches of intervention, and therefore recommends a practice guide for uniformity of practice.

\section{Recommendation}

Regarding the barriers to rehabilitation, it is noteworthy that temporary support strategies could help the mental health service users get back to the community, and back on their feet. Health professionals with psychological knowledge and counselling should be engaged in psychological interventions. Private individuals could also conduct this at no cost, such as counsellors in primary and secondary schools, course advisers in universities and religious leaders, union leaders and community leaders. These groups of individuals could help the country and the environment. The cost of skill acquisition at an Occupational Therapy Unit constitutes a significant barrier to accessing this facility. If the skills can be acquired 
at no cost, it would increase the affordability. This means the relatives would only be left with the cost of sponsoring transportation of the relatives to the hospital facility for occupational therapy. It is also worthy of note that the participants who achieved self-mastery through self-decision making with minimal assistance of their relatives were those who made an independent choice and also reported a feeling of wholesomeness compared to those who were dependent on their family and those whose choice of career was made for them by family or health professionals.

\section{Declarations}

\section{Authors' contributions}

The manuscript was drafted and designed by 0.0, and revised by N.G. Both authors agreed on the submission for publication.

\section{Conflict of interests}

The authors declare they have no conflict of interest.

\section{Funding}

This study is supported by:

1. The Consortium for Advanced Research Training in Africa (CARTA). CARTA is jointly led by the African Population and Health Research Centre and the University of the Witwatersrand and funded by the Carnegie Corporation of New York (Grant No-B 8606.R02), Sida (Grant No:54100113), the DELTAS Africa Initiative (Grant No: 107768/Z/15/Z) and Deutscher Akademischer Austauschdienst (DAAD). The DELTAS Africa Initiative is an independent funding scheme of the African Academy of Sciences (AAS)'s Alliance for Accelerating Excellence in Science in Africa (AESA) and supported by the New Partnership for Africa's Development Planning and Coordinating Agency (NEPAD Agency), with funding from the Wellcome Trust (UK) and the UK Government.

2. The Faculty of Health Science, University of the Witwatersrand, South Africa.

Grant Number: $001 \quad 254 \quad 8491102 \quad 5121105 \quad 000000 \quad 0000000000 \quad 5254$

\section{References}

Alphs, L., Bossie, C., Mao, L., Lee, E., \& Starr, H. L. (2018). Treatment effect with

paliperidone palmitate compared with oral antipsychotics in patients with recent-onset versus more chronic schizophrenia and a history of criminal justice system involvement. Early intervention in psychiatry, 12(1), 55-65.

Adinkrah, M. (2019). Crash-landings of flying witches in Ghana: Grand mystical feats or diagnosable psychiatric illnesses? Transcultural psychiatry, 56(2), 379-397.

Albrecht, M. A., Waltz, J. A., Cavanagh, J. F., Frank, M. J., \& Gold, J. M. (2019). Increased conflictinduced slowing, but no differences in conflict-induced positive or negative prediction error learning in patients with Schizophrenia. Neuropsychologia, 123, 131-140.

Amsalem, D., Hasson-Ohayon, I., Gothelf, D., \& Roe, D. (2018). How Do Service Users with Schizophrenia and Their Families Learn About the Diagnosis? Psychiatry, 81(3), 283-287.

Asher, L., Hanlon, C., Birhane, R., Habtamu, A., Eaton, J., Weiss, H. A., ... \& De Silva, M. (2018). 
Community-based rehabilitation intervention for people with Schizophrenia in Ethiopia (RISE): a 12-month mixed-methods pilot study. BMC psychiatry, 18(1), 250.

Askari, M. (2018). A comparative study of physical activity level among in-service users with Schizophrenia and bipolar disorder. International Archives of Health Sciences, 5(3), 93.

Asher, L., Hanlon, C., Birhane, R., Habtamu, A., Eaton, J., Weiss, H. A., ... \& De Silva, M. (2018).

Community-based rehabilitation intervention for people with schizophrenia in Ethiopia (RISE): a 12-month mixed-methods pilot study. BMC psychiatry, 18(1), 250.

Cullen, B. A., Mojtabai, R., Bordbar, E., Everett, A., Nugent, K. L., \& Eaton, W. W. (2017).

Social network, recovery attitudes and internal stigma among those with serious mental illness. International Journal of Social Psychiatry, 63(5), 448-458.

Chen, X., Zhang, X., Wong, S. C., Yang, M., Kong, D., \& Hu, J. (2018). Characteristics of alleged homicide offenders with and without schizophrenia in Sichuan, China. Criminal behaviour and mental health, 28(2), $202-215$.

Corbière, M., Zaniboni, S., Dewa, C. S., Villotti, P., Lecomte, T., Sultan-Taïeb, H., ... \& Fraccaroli, F. (2019).

Work productivity of people with a psychiatric disability working in social firms. Work (Preprint), 1-10.

De Jong, S., Hasson-Ohayon, I., van Donkersgoed, R. J., Timmerman, M. E., van der Gaag, M., Aleman,

A., ... \& Lysaker, P. H. (2019). Predicting therapy success from the outset: The moderating effect of insight into the illness on metacognitive psychotherapy outcome among persons with schizophrenia. Clinical psychology \& psychotherapy.

Donaldson, K. R., Roach, B. J., Ford, J. M., Lai, K., Sreenivasan, K. K., \& Mathalon, D. H. (2019). Effects

of conflict and strategic processing on neural responses to errors in schizophrenia. Biological psychology, 140, 9-18.

Evensen, S., Wisløff, T., Lystad, J. U., Bull, H., Martinsen, E. W., Ueland, T., \& Falkum, E. (2019). Exploring

the potential cost-effectiveness of a vocational rehabilitation program for individuals with schizophrenia in a high-income welfare society. $B M C$ psychiatry, 19(1), 140.

Fan, Y., Ma, N., Ma, L., Xu, W., Lamberti, J. S., \& Caine, E. D. (2018). A community-based peer support service for persons with severe mental illness in China. BMC psychiatry, 18(1), 170.

Flore, J., Kokanović, R., Callard, F., Broom, A., \& Duff, C. (2019). Unravelling subjectivity embodied experience and (taking) psychotropic medication. Social Science \& Medicine, 230, 66-73.

Page 12/16 
Firth, J., Stubbs, B., Vancampfort, D., Schuch, F. B., Rosenbaum, S., Ward, P. B., ... \& Yung, A. R. (2017).

The validity and value of the self-reported physical activity and accelerometry in people with schizophrenia: a population-scale study of the UK Biobank. schizophrenia Bulletin, 44(6), 1293-1300.

Funk, M. (2016). Global burden of mental disorders and the need for a comprehensive,

coordinated response from health and social sectors at the country level.

Gerretsen, P., Menon, M., Chakravarty, M. M., Lerch, J. P., Mamo, D. C., Remington, G., ... \& Graff-

Guerrero, A. (2015). Illness denial in schizophrenia spectrum disorders: a function of left hemisphere dominance. Human brain mapping, 36(1), 213225.

Gumley, A., \& Liotti, G. (2018). An Attachment Perspective on schizophrenia: The Role of Disorganized Attachment, Dissociation, and Mentalization. Psychosis, Trauma and Dissociation: Evolving Perspectives on Severe Psychopathology, $97-116$.

Hasan, S., \& Adil, M. (2019). Schizophrenia: a neglected problem in Pakistan. The Lancet, 394(10193),

115-116.

Hsiao, C. Y., Lu, H. L., \& Tsai, Y. F. (2018). Effect of family sense of coherence on internalized stigma

and health-related quality of life among individuals with schizophrenia. International Journal of Mental Health Nursing, 27(1), $138-146$.

Jovanovic, N., Kudumija Slijepcevic, M., \& Podlesek, A. (2019). Personality traits in suicidal and homicidal

subjects with schizophrenia. The Journal of Forensic Psychiatry \& Psychology, 30(1), 76-88.

Krippendorff, K. (2018). Content analysis: An introduction to its methodology. Sage publications.

Lempp, H., Abayneh, S., Gurung, D., Kola, L., Abdulmalik, J., Evans-Lacko, S., ... \& Hanlon, C. (2018).

Service user and caregiver involvement in the mental health system strengthening in low-and middle-income countries: a cross-country qualitative study. Epidemiology and psychiatric sciences, 27(1), 29-39.

Lim, C., Barrio, C., Hernandez, M., Barragán, A., \& Brekke, J. S. (2017). Recovery From

schizophrenia in Community-Based Psychosocial Rehabilitation Settings: Rates and Predictors. Research on Social Work Practice, $27(5), 538-551$. https://doi.org/10.1177/1049731515588597.

Loh, S. Y. (2018). Interdisciplinary Rehabilitation to Facilitate Recovery of People Living with Long-Term 
schizophrenia in Developing Countries. Psychotic Disorders: An Update, 63.

Lucas, J. W., \& Phelan, J. C. (2018). Influence and Social Distance Consequences across

Categories of Race and Mental IIIness. Society and Mental Health, 2156869318761125.

Marder, S. R., \& Galderisi, S. (2017). The current conceptualisation of negative symptoms in schizophrenia. World Psychiatry, 16(1), 14-24.

Moorkath, F., Vranda, M. N., \& Naveenkumar, C. (2019). Women with mental illness-An overview of sociocultural factors influencing family rejection and subsequent institutionalization in India. Indian Journal of Psychological Medicine, 41 (4), 306.

Moritz, D., \& Roberts, J. E. (2018). Self-other agreement and meta-perception accuracy across the Big Five: Examining the roles of depression and self-esteem. Journal of Personality, 86(2), 296-307.

Nehrlich, A. D., Gebauer, J. E., Sedikides, C., \& Abele, A. E. (2019). Individual self-> relational self-> collective self-But why? Processes driving the self-hierarchy in self-and person perception. Journal of Personality, 87(2), 212-230.

Oyelade, O. O., \& Ayandiran, E. O. (2018). Violence Management in a Nigerian Psychiatric Facility:

Psychiatric-Mental Health Nurses' Current Practices and Their Effectiveness. Journal of Psychosocial Nursing and Mental Health Services, 56(11), $37-45$.

Rai, S., Gurung, D., Kaiser, B. N., Sikkema, K. J., Dhakal, M., Bhardwaj, A., \& Kohrt, B. A. (2018). A service user co-facilitated intervention to reduce mental illness stigma among primary healthcare workers: Utilizing perspectives of family members and caregivers. Families, Systems, \& Health, 36(2), 198.

Sánchez, J., Sung, C., Phillips, B. N., Tschopp, M. K., Muller, V., Lee, H. L., \& Chan, F. (2019). Predictors

of perceived social effectiveness of individuals with serious mental illness. Psychiatric Rehabilitation Journal, 42(1), 88.

Seshadri, K., Sivakumar, T., \& Jagannathan, A. (2019). The Family Support Movement and schizophrenia in India. Current psychiatry reports, 21(10), 95.

Seeman, M. V. (2018). Women who suffer from schizophrenia: Critical issues - World Journal of Psychiatry, 8(5), 125.

Smartt, C., Prince, M., Frissa, S., Eaton, J., Fekadu, A., \& Hanlon, C. (2019). Homelessness and severe 
mental illness in low-and middle-income countries: scoping review. BJPsych Open, 5(4).

Souraya, S., Hanlon, C., \& Asher, L. (2018). Involvement of people with schizophrenia in decision-making

in rural Ethiopia: a qualitative study. Globalization and health, 14(1), 85.

Son, D. (2018). My psychosis and meds. Psychosis, 10(3), 228-234.

Uys L. R. \& Middleton Lyn (2014) Mental Health Nursing: A South African Perspective -

https://books.google.com/books/about/Mental_Health_Nursing.html. A South African Perspective. Edition, 6. Juta, 1 - 864

World Health Organization (2012). Metrics: Disability Adjusted Life Years: Quantifying the

burden of mortality and morbidity, http://www.who.int/healthinfo/global_burden_disease/metrics_daly/en/

World Health Organization. (2013). Mental health action plan 2013-2020. World Health

Organization. Retrieved from http://www.who.int/mental_health/publications/action_plan/en/. Pdf (accessed 5th March, 2014). ISBN 978 92 4

1506021.

World Health Organization (2014) Mental Health Atlas - World Health Organization

www.who.int/mental_health/evidence/atlas/mental_health_atlas_2014/en/

World Health Organization (2018) International Guidelines on Health-Related

Rehabilitationhttps://www.researchgate.net/.../273139344_WHO_International_Guidelines_on_Health...www.who.int/medicines/areas/.../validationwithout_appendices_2016_05_17.pdf

\section{Figures}

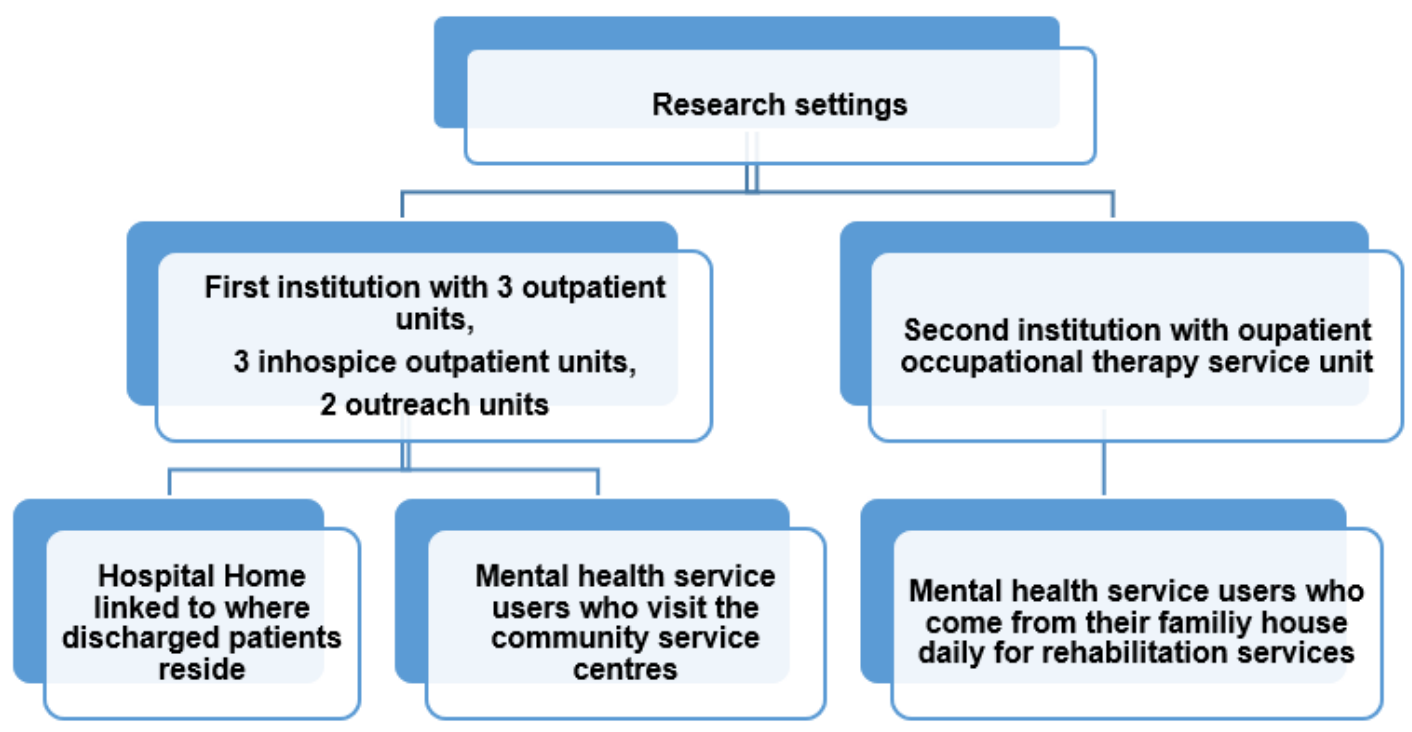


Figure 1

A schematic representation of the research setting

Page 16/16 